\title{
Prepared and highly committed despite the risk of COVID-19 infection: a cross-sectional survey of primary care physicians' concerns and coping strategies in Singapore
}

Jerrald Lau ${ }^{1,2}$, David Hsien-Yung Tan 3,4, Gretel Jianlin Wong 1,2, Yii-Jen Lew ${ }^{3}$, Ying-Xian Chua ${ }^{3}$, Lian-Leng Low ${ }^{4,5,6}$, Han-Kwee Ho ${ }^{7}$, Thiam-Soo Kwek ${ }^{8}$, Sue-Anne Ee-Shiow Toh ${ }^{2,9}$ and Ker-Kan Tan ${ }^{2,9^{*}}$ id

\begin{abstract}
Background: Primary care physicians (PCPs) are first points-of-contact between suspected cases and the healthcare system in the current COVID-19 pandemic. This study examines PCPs' concerns, impact on personal lives and work, and level of pandemic preparedness in the context of COVID-19 in Singapore. We also examine factors and coping strategies that PCPs have used to manage stress during the outbreak.

Methods: Two hundred and sixteen PCPs actively practicing in either a public or private clinic were cluster sampled via email invitation from three primary care organizations in Singapore from 6th to 29th March 2020. Participants completed a cross-sectional online questionnaire consisting of items on work- and non-work-related concerns, impact on personal and work life, perceived pandemic preparedness, stress-reduction factors, and personal coping strategies related to COVID-19.

Results: A total of 158 questionnaires were usable for analyses. PCPs perceived themselves to be at high risk of COVID-19 infection (89.9\%), and a source of risk (74.7\%) and concern (71.5\%) to loved ones. PCPs reported acceptance of these risks (91.1\%) and the need to care for COVID-19 patients (85.4\%). Overall perceived pandemic preparedness was extremely high (75.9 to $89.9 \%)$. PCPs prioritized availability of personal protective equipment, strict infection prevention guidelines, accessible information about COVID-19, and well-being of their colleagues and family as the most effective stress management factors.

Conclusions: PCPs continue to serve willingly on the frontlines of this pandemic despite the high perception of risk to themselves and loved ones. Healthcare organizations should continue to support PCPs by managing both their psychosocial (e.g. stress management) and professional (e.g. pandemic preparedness) needs.
\end{abstract}

Keywords: COVID-19, Primary care, Psychosocial impact, Pandemic preparedness, Cross-sectional

\footnotetext{
* Correspondence: surtkk@nus.edu.sg

${ }^{2}$ Singapore Population Health Improvement Centre (SPHERiC), National University Health System, Singapore, Singapore

${ }^{9}$ Yong Loo Lin School of Medicine, National University of Singapore, NUHS Tower Block, Level 8, 1 E Kent Ridge Road, Singapore 119228, Singapore

Full list of author information is available at the end of the article
}

(c) The Author(s). 2021 Open Access This article is licensed under a Creative Commons Attribution 4.0 International License, which permits use, sharing, adaptation, distribution and reproduction in any medium or format, as long as you give appropriate credit to the original author(s) and the source, provide a link to the Creative Commons licence, and indicate if changes were made. The images or other third party material in this article are included in the article's Creative Commons licence, unless indicated otherwise in a credit line to the material. If material is not included in the article's Creative Commons licence and your intended use is not permitted by statutory regulation or exceeds the permitted use, you will need to obtain permission directly from the copyright holder. To view a copy of this licence, visit http://creativecommons.org/licenses/by/4.0/ The Creative Commons Public Domain Dedication waiver (http://creativecommons.org/publicdomain/zero/1.0/) applies to the data made available in this article, unless otherwise stated in a credit line to the data. 


\section{Background}

The World Health Organisation (WHO) has characterized the novel Coronavirus Disease 2019 (COVID-19) outbreak as a pandemic, with 57,882,183 confirmed cases and 1,377,395 deaths globally as of 22nd November 2020 [1]. Much academic and media coverage on healthcare workers has rightly focused on the rigours faced by frontline hospital staff. However, it is often easy to forget the critical role played by primary care physicians (PCP) during this health crisis, as individuals who develop a febrile illness or respiratory symptoms are likely to first seek treatment from a PCP. This means that PCPs are often the first medical professionals to encounter suspected COVID-19 cases and will need to make crucial decisions on how to manage these cases appropriately in order to limit community spread.

PCPs in Singapore generally fall under two models of practice. Public clinics (i.e. polyclinics) operate in a group practice setting and provide subsidized primary care, accounting for approximately $21 \%$ of all primary care outpatient visits in the country $[2,3]$. Private clinics (i.e. general practitioners, family medicine clinics) may be operated by PCPs as either a single-individual practice or a group practice, and account for the remaining $79 \%$ of outpatient visits [2, 3]. With 20 polyclinics and approximately 1700 private clinics, including eight family medicine clinics, the crucial role of primary care in managing the COVID-19 outbreak in Singapore is underscored by the Public Health Preparedness Clinic (PHPC) scheme, which provides government assistance to approximately 940 private practice PCPs with financial subventions, personal protective equipment (PPEs) and medical supplies from the national stockpile during public health emergencies, as well as continued professional training to build outbreak management capacity $[4,5]$. This support has not been misplaced; as of 17th March 2020, 108 of the 158 locally transmitted COVID-19 cases (68.4\%) had visited a PCP before being diagnosed [6]. The role of primary care in this pandemic is also highlighted elsewhere across the world in guidelines and literature that acknowledge how PCPs are often first points-of-contact between suspected cases and the healthcare system [7-10].

A commonly overlooked angle is the potential psychosocial impact of the outbreak on PCPs as they place themselves at increased infection risk. For example, while the efforts of healthcare professionals were publicly lauded during the Severe Acute Respiratory Syndrome (SARS) outbreak, these same professionals were treated with a degree of fear and prejudice by laypeople in social spaces and on public transport [11-13]. PCPs serving the community in Hong Kong during this period also reported high levels of anxiety about their own wellbeing and the safety of their immediate families [14]. In addition, potentially detrimental deviations to PCPs' standard clinical practice in order to prevent infection (e.g. avoiding physical examination of patients) were observed [14]. Studies conducted to understand the pandemic preparedness of PCPs and other healthcare professionals during the $\mathrm{H} 5 \mathrm{~N} 1$ avian influenza outbreak also found that the majority (80-95\%) of PCPs were concerned that their profession would put their own health at risk; over half felt that family, friends or the general public would avoid them due to possible contact with $\mathrm{H} 5 \mathrm{~N} 1$ cases during the outbreak $[2,15]$. Similarly, studies conducted to examine the emotional impact, concerns and coping strategies of healthcare professionals regarding Middle Eastern Respiratory Syndrome (MERS-CoV) suggested that the majority felt at risk of being infected in their workplace but ethically obligated to continue caring for patients during the outbreak [16, 17] When asked to share about what would motivate them in future pandemics, healthcare professionals reported that 1) organizational support to increase outbreak preparedness, 2) an assurance of financial and emotional support for their family members while they worked overtime to care for patients, and 3) appreciation from health authorities, supervisors and the public were the most important factors [17].

To our understanding, no prior study has yet examined the social and psychological impact of the COVID19 outbreak on PCPs. Given the critical role that primary care must perform in containing and mitigating this global public health crisis, the current research seeks to understand the concerns and perceived pandemic preparedness of PCPs in Singapore in the context of the COVID-19 situation. We also examine PCPs' personal coping strategies and perceived impact of the outbreak on their personal and professional lives.

\section{Methods \\ Study design and setting}

As the exigencies of COVID-19 outbreak control measures in Singapore discouraged face-to-face interaction between research teams and potential participants, the present research utilized a cross-sectional online design. Participants were cluster sampled via email invitation disseminated by three organizations: the National University Health System (NUHS) Primary Care Network (PCN), National University Polyclinics (NUP), and the College of Family Physicians Singapore (CFPS). NUHS is one of the three integrated public healthcare systems in Singapore, with a catchment area approximating 1.1 million residents in the western region of the island [18]. The PCN and NUP are member organizations that coordinate and manage private and public primary care clinics respectively within the NUHS catchment area $[19,20]$. The CFPS is a professional 
society that provides vocational and continued professional development for PCPs and other family medicine practitioners in Singapore [21].

The sampling frame comprised of all medical doctors who were either 1) a PCP practicing within an NUP polyclinic, or 2) a PCP practicing within an NUHS PCN private clinic, or 3) a Member or Fellow of the CFPS, and 4) had a registered email address within the respective organizations. This resulted in a total of 2866 viable email addresses, although there was the possibility of overlap as potential participants could have been part of either NUP or NUHS PCN and also a member of the CFPS. To protect the confidentiality of PCPs, individual email addresses were not released to the study team. The data collection period lasted from 6th March 2020 to 29th March 2020.

To put this study in perspective, Singapore began implementing its COVID-19 outbreak response upon diagnosing the first confirmed case on 23rd January 2020. The country raised its Disease Outbreak Response System Condition (DORSCON) to "Orange" (i.e. the same level of severity as during the SARS period) on 7th February 2020.

\section{Measures}

The anonymous self-administered online questionnaire (see Supplementary File 1) was adapted from prior studies on PCPs and healthcare workers during the H5N1 avian influenza and MERS-CoV outbreaks $[2,15,17]$. The questionnaire was administered via the REDCap web application for data collection and management [22].

The first three sections consisted of statements adapted from Wong and colleagues' H5N1 study, grouped into work- and non-work-related concerns (16 items), perceived impact on personal life and work (10 items), and outbreak preparedness (six items), all with reference to COVID-19 [2]. The questionnaire also included statements from Khalid and colleagues' study on MERS-CoV; these were grouped into two sections on factors that might help PCPs reduce stress (13 items), and personal coping strategies to alleviate stress (13 items), during the COVID-19 outbreak [17]. Participants responded to these items using 4-point Likert-type scales (e.g. strongly disagree, disagree, agree, strongly agree).

In addition, participants also provided demographic data consisting of gender, broad age band, ethnicity, marital status, number of children (if married, divorced, or widowed), whether residing with family or alone, number of people living in the same household, type of primary care practice, years of experience in medical practice, and highest professional or academic medical qualification.

\section{Statistical analyses}

All statistical analyses were performed using IBM SPSS Statistics Version 22.0 [23]. Frequencies and proportions were used to present participant demographic data.

Frequencies and proportions were used to present data for the statements on work-related and non-workrelated concerns, perceived impact on personal life and work, and outbreak preparedness. We dichotomized participant responses for the 4-point Likert-type scales into "agreement" (i.e. strongly agree, agree) and "disagreement" (i.e. strongly disagree, disagree) responses. Cronbach's alpha was used to assess internal consistency for the items within each of these three sections.

Participant responses on the statements about factors that might help reduce stress were converted into a point-based system (i.e. "extremely effective" being worth four points, to "not at all effective" being worth one point). Similarly, responses for the statements on personal coping strategies were converted into a pointbased system (i.e. "always used" being worth four points, to "never used" being worth one point). Points per item were summarised across the sample and the items ranked accordingly.

\section{Ethics approval}

Ethical approval to conduct this study was provided by the National University of Singapore's Institutional Review Board (Reference Code S-20-071) in accordance with the Declaration of Helsinki. Informed consent to participate was obtained from all participants.

\section{Results}

\section{Sample demographics}

A total of 216 PCPs provided informed consent to participate in the online questionnaire $(7.54 \%$ response rate). Of these, 58 questionnaires were unusable (defined as having at least two sections incomplete), leaving a final sample of 158 participants. The sample was predominantly of Chinese ethnicity (80.4\%), married $(84.2 \%)$ and residing with family $(91.8 \%)$. There were more private than public practice PCPs (61.5\%). A full description of sample demographics can be found in Table 1.

\section{Work- and non-work-related concerns}

Nearly all PCPs felt that their job would put them at high risk of exposure to COVID-19 (89.9\%), and the majority agreed or strongly agreed that they were worried about falling ill with the disease (69.0\%). Most PCPs were also concerned about the risks that they posed to loved ones because of their job $(74.7 \%)$ and the majority felt that their loved ones would likewise be worried about being infected by them (71.5\%). However, PCPs disagreed that they should not be looking after COVID- 
Table 1 Sociodemographic characteristics of the sample

\begin{tabular}{|c|c|}
\hline Characteristic & PCPs $(N=158)$ \\
\hline Gender, Male - no. (\%) & $83(52.5)$ \\
\hline \multicolumn{2}{|l|}{ Age - no. (\%) } \\
\hline 20-29 years & $10(6.3)$ \\
\hline 30-39 years & $63(39.9)$ \\
\hline 40-49 years & $45(28.5)$ \\
\hline 50 years and above & $40(25.3)$ \\
\hline \multicolumn{2}{|l|}{ Ethnicity - no. (\%) } \\
\hline Chinese & $127(80.4)$ \\
\hline Malay & $3(1.9)$ \\
\hline Indian & $19(12.0)$ \\
\hline Other & $9(5.7)$ \\
\hline \multicolumn{2}{|l|}{ Marital status - no. (\%) } \\
\hline Single & $21(13.3)$ \\
\hline Married & $133(84.2)$ \\
\hline Divorced & $4(2.5)$ \\
\hline \multicolumn{2}{|l|}{ Living with - no. (\%) } \\
\hline Family & $145(91.8)$ \\
\hline Alone & $9(5.7)$ \\
\hline Others (e.g. roommate) & $4(2.5)$ \\
\hline \multicolumn{2}{|l|}{ Type of medical practice - no. (\%) } \\
\hline General practitioner & $78(49.4)$ \\
\hline In a Public Health Preparedness Clinic - no. (\%) & $65(83.3)^{a}$ \\
\hline Family medicine clinic & $11(7.0)$ \\
\hline Polyclinic & $53(33.5)$ \\
\hline Restructured hospital & $8(5.1)$ \\
\hline Others (e.g. locum) & $8(5.1)$ \\
\hline \multicolumn{2}{|l|}{ Years of medical experience - no. (\%) } \\
\hline $1-5$ years & $23(14.6)$ \\
\hline $6-10$ years & $38(24.1)$ \\
\hline $11-15$ years & $23(14.6)$ \\
\hline $16-20$ years & $26(16.5)$ \\
\hline More than 20 years & $48(30.4)$ \\
\hline \multicolumn{2}{|l|}{ Highest medical qualification - no. (\%) } \\
\hline Bachelor of Medicine, Bachelor of Surgery (MBBS) & $50(31.6)$ \\
\hline Graduate Diploma in Family Medicine & $55(34.8)$ \\
\hline Master of Medicine (Family Medicine) & $17(10.8)$ \\
\hline Member of the College of Family Physicians & $11(7.0)$ \\
\hline Fellow of the College of Family Physicians & $14(8.9)$ \\
\hline Others & $11(7.0)$ \\
\hline
\end{tabular}

Note: "PCPs" refer to primary care providers

aProportion calculated using general practitioners $(n=78)$ as denominator

19 patients $(85.4 \%)$ and did not feel that the risk they were exposed to was unacceptable (89.9\%); almost all agreed that they accepted the risk of COVID-19 infection as part of the job (91.1\%). Similarly, PCPs disagreed that they would leave their profession because of these risks (93.0\%). The Cronbach's $\alpha$ for work- and nonwork-related concerns was 0.85 , suggesting acceptable reliability [24]. Response frequencies and proportions for each statement are presented in Table 2.

\section{Perceived impact on personal life and work}

The majority of PCPs perceived that they would feel more stressed at work (73.4\%), experience an increase in workload (67.1\%) and would have to engage in work not usually done by them (70.3\%). Most PCPs disagreed that they would avoid telling their loved ones about the risks they were exposed to $(78.5 \%)$ or the nature of their job (81.6\%). Most PCPs also did not think that there would be more intra-workplace conflict during this COVID-19 period (71.5\%). The Cronbach's $\alpha$ for perceived impact on personal life and work was 0.75 . Response frequencies and proportions for each statement are presented in Table 3.

\section{Outbreak preparedness}

The agreement was high (75.9 to $89.9 \%$ ) for every item in this section. Notably, the top three statements were that PCPs felt personally prepared for the COVID-19 outbreak (89.9\%), that they had received adequate PPE training $(88.6 \%)$, and they had someone to turn to if they were unsure of the use of PPEs (86.1\%). The Cronbach's $\alpha$ for outbreak preparedness was 0.85 . Response frequencies and proportions for each statement are presented in Table 4.

\section{Factors that might help reduce stress and personal coping strategies}

The five highest-ranked (i.e. proportion of sample rating moderately or extremely effective) stress-reduction factors were 1) PPEs being provided to PCPs by their workplace $(96.2 \%), 2$ ) clear guidelines for infection prevention (95.0\%), 3) no COVID-19 infections among colleagues after implementing protective measures $(93.6 \%), 4)$ loved ones not being infected (92.4\%), and 5) confidence in fellow medical colleagues should the PCPs themselves be infected with COVID-19 (91.1\%). The five most often utilized (i.e. proportion of sample rating often or always used) coping strategies by PCPs during this COVID-19 outbreak were 1) following strict personal protective measures $(90.5 \%), 2$ ) reading about COVID-19, its transmission mechanisms and prevention $(89.2 \%), 3)$ engaging in relaxation activities such as exercise and prayers $(64.0 \%), 4)$ avoiding public spaces to minimize exposure risk (60.1\%), and 5) communicating with loved ones for stress relief and emotional support (57.0\%). Scores and subsequent rankings for each statement are presented in Table 5. 
Table 2 Frequencies and proportions for work- and non-work-related concerns $(N=158)^{a}$

\begin{tabular}{|c|c|c|c|c|}
\hline \multirow[t]{2}{*}{ Statement } & \multicolumn{2}{|c|}{ Disagreement } & \multicolumn{2}{|c|}{ Agreement } \\
\hline & SD (\%) & D (\%) & $A(\%)$ & SA (\%) \\
\hline \multicolumn{5}{|l|}{ Work-related concerns } \\
\hline My job would put me at great exposure risk & $1(0.6)$ & $15(9.5)$ & $94(59.5)$ & $48(30.4)$ \\
\hline I am afraid of falling ill with COVID-19 & $7(4.4)$ & $42(26.6)$ & $83(52.5)$ & $26(16.5)$ \\
\hline I should not be looking after COVID-19 patients & $54(34.2)$ & $81(51.3)$ & $18(11.4)$ & $5(3.2)$ \\
\hline The risk I am exposed to is not acceptable & $35(22.2)$ & $107(67.7)$ & $10(6.3)$ & $6(3.8)$ \\
\hline I accept that the risk of contracting COVID-19 is part of my job & $1(0.6)$ & $13(8.2)$ & $100(63.3)$ & $44(27.8)$ \\
\hline I might look for another job because of the risks & $92(58.2)$ & $55(34.8)$ & $9(5.7)$ & $2(1.3)$ \\
\hline It is acceptable if my colleagues resign because of their fears & $19(12.0)$ & $53(33.5)$ & $74(46.8)$ & $12(7.6)$ \\
\hline I am confident my employer would look after my needs & $11(7.0)$ & $22(13.9)$ & $104(65.8)$ & $21(13.3)$ \\
\hline \multicolumn{5}{|l|}{ Non-work-related concerns } \\
\hline People close to me would be at high risk of getting COVID-19 because of my job & $4(2.5)$ & $36(22.8)$ & $89(56.3)$ & $29(18.4)$ \\
\hline In particular, I would be concerned for my spouse/ partner & $5(3.2)$ & $27(17.1)$ & $83(52.5)$ & $43(27.2)$ \\
\hline In particular, I would be concerned for my parents & $7(4.4)$ & $29(18.4)$ & $78(49.4)$ & $44(27.8)$ \\
\hline In particular, I would be concerned for my children & $7(4.4)$ & $30(19.0)$ & $74(46.8)$ & $47(29.7)$ \\
\hline In particular, I would be concerned for my close friends & $8(5.1)$ & $61(38.6)$ & $73(46.2)$ & $16(10.1)$ \\
\hline In particular, I would be concerned for my work colleagues & $9(5.7)$ & $32(20.3)$ & $96(60.8)$ & $21(13.3)$ \\
\hline People close to me would be worried for my health & $5(3.2)$ & $22(13.9)$ & $97(61.4)$ & $34(21.5)$ \\
\hline People close to me would be worried as they may get infected by me & $5(3.2)$ & $40(25.3)$ & $97(61.4)$ & $16(10.1)$ \\
\hline
\end{tabular}

${ }^{a} S D$ Strongly disagree, $D$ Disagree, $A$ Agree, $S A$ Sstrongly agree

\section{Discussion}

This study was a cross-sectional exploratory survey of PCPs' concerns, perceived pandemic preparedness, possible stress-reduction and coping strategies in the context of the COVID-19 outbreak in Singapore. We found that PCPs perceived themselves to be at high risk of COVID-19 infection and a source of risk and concern to loved ones. Nonetheless, they reported acceptance of these risks and the need to care for COVID-19 patients. Overall perceived pandemic preparedness was extremely high. PCPs prioritized availability of personal protective equipment, strict infection prevention guidelines, accessible information about COVID-19, and well-being of their colleagues and family as the most effective stress management factors.

\section{PCPs' concerns, impact on work and personal life, and outbreak preparedness}

The majority of PCPs perceived themselves as being at risk of COVID-19 infection and were concerned about the risks that they could be bringing to their loved ones. Interestingly, unlike findings from similar studies conducted in

Table 3 Frequencies and proportions for perceived impact on personal life and work $(N=158)^{a}$

\begin{tabular}{|c|c|c|c|c|}
\hline \multirow[t]{2}{*}{ Statement } & \multicolumn{2}{|c|}{ Disagreement } & \multicolumn{2}{|c|}{ Agreement } \\
\hline & SD (\%) & $\mathrm{D}(\%)$ & $\mathrm{A}(\%)$ & SA (\%) \\
\hline I would be afraid of telling my family about the risks I am exposed to & $31(19.6)$ & $93(58.9)$ & $28(17.7)$ & $6(3.8)$ \\
\hline People would avoid me because of my job & $12(7.6)$ & $86(54.4)$ & $54(34.2)$ & $6(3.8)$ \\
\hline People would avoid my family members because of my job & $26(16.5)$ & $92(58.2)$ & $36(22.8)$ & $4(2.5)$ \\
\hline I would avoid telling other people about the nature of my job & $36(22.8)$ & $93(58.9)$ & $26(16.5)$ & $3(1.9)$ \\
\hline There would be adequate staff at my workplace to handle the increased demand & $18(11.4)$ & $66(41.8)$ & $70(44.3)$ & $4(2.5)$ \\
\hline There would be more conflict amongst colleagues at work & $17(10.8)$ & $96(60.8)$ & $40(25.3)$ & $5(3.2)$ \\
\hline I would feel more stressed at work & $6(3.8)$ & $36(22.8)$ & $93(58.9)$ & $23(14.6)$ \\
\hline I would have an increase in workload & $6(3.8)$ & $46(29.1)$ & $88(55.7)$ & $18(11.4)$ \\
\hline I would have to work overtime & $6(3.8)$ & $74(46.8)$ & $59(37.3)$ & $19(12.0)$ \\
\hline I would have to do work not normally done by me & $4(2.5)$ & $43(27.2)$ & $83(52.5)$ & $28(17.7)$ \\
\hline
\end{tabular}

${ }^{a} S D$ Strongly disagree, D Disagree, A Agree, SA Strongly agree 
Table 4 Frequencies and proportions for perceived outbreak preparedness $(N=158)^{a}$

\begin{tabular}{|c|c|c|c|c|}
\hline \multirow[t]{2}{*}{ Statement } & \multicolumn{2}{|c|}{ Disagreement } & \multicolumn{2}{|c|}{ Agreement } \\
\hline & SD (\%) & $\mathrm{D}(\%)$ & $A(\%)$ & SA (\%) \\
\hline I have received training for infection control at my workplace & $9(5.7)$ & $29(18.4)$ & $93(58.9)$ & $27(17.1)$ \\
\hline I have received adequate personal protective equipment training & $6(3.8)$ & $12(7.6)$ & $104(65.8)$ & $36(22.8)$ \\
\hline I have someone to turn to if unsure of the use of personal protective equipment & $5(3.2)$ & $17(10.8)$ & $98(62.0)$ & $38(24.1)$ \\
\hline My workplace has a preparedness plan for a COVID-19 outbreak & $3(1.9)$ & $24(15.2)$ & $89(56.3)$ & $42(26.6)$ \\
\hline My workplace is prepared for a COVID-19 outbreak & $6(3.8)$ & $19(12.0)$ & $96(60.8)$ & $37(23.4)$ \\
\hline I am personally prepared for a COVID-19 outbreak & $5(3.2)$ & $11(7.0)$ & $112(70.9)$ & $30(19.0)$ \\
\hline The is sufficient supply of personal protective equipment for use in my workplace & $4(2.5)$ & $22(13.9)$ & $101(63.9)$ & $31(19.6)$ \\
\hline I have received training for infection control at my workplace & $9(5.7)$ & $29(18.4)$ & $93(58.9)$ & $27(17.1)$ \\
\hline I have received adequate personal protective equipment training & $6(3.8)$ & $12(7.6)$ & $104(65.8)$ & $36(22.8)$ \\
\hline I have someone to turn to if unsure of the use of personal protective equipment & $5(3.2)$ & $17(10.8)$ & $98(62.0)$ & $38(24.1)$ \\
\hline
\end{tabular}

${ }^{a} S D$ Strongly disagree, $D$ Disagree, $A$ Agree, $S A$ Strongly agree

Singapore during the SARS and H5N1 outbreaks, most PCPs did not feel that they or their loved ones would face social stigmatisation [2, 25]. Moreover, the majority did not feel the need to hide the nature of their work or the risks that they could potentially face from loved ones and the public. Only a very small proportion of PCPs had considered resigning from their jobs, and the acceptance and readiness to provide medical care for COVID-19 patients was very high. PCPs differed in their opinions on colleagues resigning due to their fears, although a higher proportion (54.4\%) responded with acceptance. Most seemed to feel that the COVID-19 outbreak would increase their workload and work-related stress, and have to take on work not normally performed by them, but would not otherwise be a cause of workplace conflict. These encouraging findings suggest a high level of ethical obligation and medical professionalism in our sample of PCPs to continue serving their communities, despite the personal and family risks incurred. Health authorities and institutions should continue to keep watch for signs of burnout among PCPs as they suffer increased stress and take on both a higher level of workload and range of tasks during this pandemic; international evidence from prior outbreaks has shown the vulnerability of frontline healthcare professionals to long-term psychological outcomes such as anxiety, depression, and post-traumatic stress disorder $[26,27]$.

Perceived preparedness for the COVID-19 outbreak was extremely high amongst the sample. There are two possible reasons for this encouraging finding. Firstly, the Singapore Ministry of Health has gradually strengthened overall pandemic preparedness within the healthcare system since the national experiences of SARS and H1N1, which has resulted in readily available outbreak response frameworks, guidelines and protocols for both healthcare professionals and the lay public [28]. The second possibility is that nearly two-thirds of the private practice PCPs in our sample were members of PHPCs. Under this scheme, their medical practices would specifically have been prepared for outbreak management with 3 months' worth of PPEs provided at no cost, priority medical supplies, and standardized training on infection prevention measures $[4,29]$. These government-funded schemes are likely to have facilitated a high level of pandemic preparedness - in terms of PPE availability and infection prevention training - among Singaporean PCPs as compared to healthcare professionals in other, less-resourced settings [30-32].

\section{Stress management and coping strategies among PCPs}

Clear infection prevention guidelines and personal protective measures, access to information about COVID19 and a reliable supply of PPEs were the most important factors for PCPs in coping with stress during the outbreak. This corroborates with what has been reported in SARS and MERS-CoV, where safety precautions and prompt knowledge about the disease were key motivators in incentivizing healthcare professionals to continue providing medical care through an outbreak [17, 33, 34]. PCPs also rated the prevention of their medical colleagues and loved ones from being infected with COVID-19 as the next most important factor in their own stress management. This is perhaps expected given the aforementioned finding that PCPs perceived themselves as being a source of infection risk and concern to their family members due to the nature of caring for COVID-19 patients.

As it was with healthcare professionals during the SARS, H1N1 and MERS-CoV outbreaks, PCPs are likely to suffer immense emotional pressure should their colleagues and loved ones fall victim to COVID-19; considerable research has also highlighted the tendency for healthcare professionals to disregard their own physical and mental wellbeing, especially during crises [17, 33, 
Table 5 Response frequencies and summed scores for stress reduction factors and personal coping strategies

\begin{tabular}{|c|c|c|c|c|c|}
\hline Statement & $\begin{array}{l}\text { Not at all } \\
\text { effective }^{a} \\
(\%)\end{array}$ & $\begin{array}{l}\text { Mildly } \\
\text { effective }^{a} \\
(\%)\end{array}$ & $\begin{array}{l}\text { Moderately } \\
\text { effective }^{\mathrm{a}}(\%)\end{array}$ & $\begin{array}{l}\text { Extremely } \\
\text { effective }^{a} \\
\text { (\%) }\end{array}$ & $\begin{array}{l}\text { Summed } \\
\text { Score }\end{array}$ \\
\hline \multicolumn{6}{|l|}{ Factors that might help reduce stress $(N=158)$} \\
\hline Positive attitude from colleagues in your workplace & $1(0.6)$ & $15(9.5)$ & $70(44.3)$ & $72(45.6)$ & 529 \\
\hline $\begin{array}{l}\text { None of your colleagues getting COVID-19 after starting strict protect- } \\
\text { ive measures }\end{array}$ & $2(1.3)$ & $8(5.1)$ & $59(37.3)$ & $89(56.3)$ & 551 \\
\hline Improvement in COVID-19 patients' condition & $5(3.2)$ & $24(15.2)$ & $78(49.4)$ & $51(32.3)$ & 491 \\
\hline Clear guidelines from workplace for infection prevention & $0(0.0)$ & $8(5.1)$ & $63(39.9)$ & $87(55.1)$ & 553 \\
\hline Personal protective equipment provided to you by workplace & $1(0.6)$ & $5(3.2)$ & $50(31.6)$ & $102(64.6)$ & 569 \\
\hline Your family members or friends not getting COVID-19 & $2(1.3)$ & $10(6.3)$ & $56(35.4)$ & $90(57.0)$ & 550 \\
\hline Decrease in COVID-19 cases reported in the news & $8(5.1)$ & $22(13.9)$ & $56(35.4)$ & $72(45.6)$ & 508 \\
\hline $\begin{array}{l}\text { Likelihood that you would get extra compensation for your exposure } \\
\text { to COVID-19 }\end{array}$ & $20(12.7)$ & $38(24.1)$ & $51(32.3)$ & $49(31.0)$ & 445 \\
\hline All healthcare professionals working together on the front line & $2(1.3)$ & $20(12.7)$ & $56(35.4)$ & $80(50.6)$ & 530 \\
\hline Confidence in fellow medical staff in case you got sick from COVID-19 & $4(2.5)$ & $10(6.3)$ & $64(40.5)$ & $80(50.6)$ & 536 \\
\hline Not having to do overtime & $11(7.0)$ & $37(23.4)$ & $57(36.1)$ & $53(33.5)$ & 468 \\
\hline Sharing jokes or humour among colleagues & $12(7.6)$ & $26(16.5)$ & $67(42.4)$ & $53(33.5)$ & 477 \\
\hline Getting free meals at your workplace & $30(19.0)$ & $43(27.2)$ & $50(31.6)$ & $35(22.2)$ & 406 \\
\hline Statement & $\begin{array}{l}\text { Never used } \\
(\%)\end{array}$ & $\begin{array}{l}\text { Sometimes } \\
\text { used }^{\text {b }}(\%)\end{array}$ & $\begin{array}{l}\text { Often used } \\
(\%)\end{array}$ & $\begin{array}{l}\text { Always } \\
\text { used }^{6}(\%)\end{array}$ & $\begin{array}{l}\text { Summed } \\
\text { Score }\end{array}$ \\
\hline \multicolumn{6}{|l|}{ Personal coping strategies $(N=157)$} \\
\hline Followed strict personal protective measures & $0(0.0)$ & $14(8.9)$ & $59(37.3)$ & $84(53.2)$ & 541 \\
\hline $\begin{array}{l}\text { Kept separate clothes for work or used scrubs to minimize risk of } \\
\text { transmission }\end{array}$ & $41(25.9)$ & $29(18.4)$ & $36(22.8)$ & $51(32.3)$ & 411 \\
\hline $\begin{array}{l}\text { Considered every patient encountered as COVID-19 case and using full } \\
\text { protective gear even if patient was COVID-19 negative }\end{array}$ & $43(27.2)$ & $44(27.8)$ & $34(21.5)$ & $36(22.8)$ & 377 \\
\hline Read about COVID-19, its prevention and mechanisms of transmission & $1(0.6)$ & $15(9.5)$ & $70(44.3)$ & $71(44.9)$ & 525 \\
\hline Avoided going out to public places to minimize COVID-19 exposure & $14(8.9)$ & $48(30.4)$ & $64(40.5)$ & $31(19.6)$ & 426 \\
\hline Did relaxation activities (e.g. involved in prayers, sports, exercise etc.) & $15(9.5)$ & $41(25.9)$ & $66(41.8)$ & $35(22.2)$ & 435 \\
\hline Talked to family and friends to relieve stress and obtain support & $13(8.2)$ & $54(34.2)$ & $61(38.6)$ & $29(18.4)$ & 420 \\
\hline Motivational self-talk to face COVID-19 outbreak with positive attitude & $60(38.0)$ & $50(31.6)$ & $29(18.4)$ & $18(11.4)$ & 319 \\
\hline $\begin{array}{l}\text { Talked to fellow colleagues or other doctors to relieve stress and } \\
\text { obtain support }\end{array}$ & $14(8.9)$ & $64(40.5)$ & $57(36.1)$ & $22(13.9)$ & 401 \\
\hline $\begin{array}{l}\text { Tried to be busy at home in activities that would keep your mind } \\
\text { away from COVID-19 }\end{array}$ & $43(27.2)$ & $56(35.4)$ & $39(24.7)$ & $19(12.0)$ & 348 \\
\hline Avoided doing overtime to reduce exposure to COVID-19 patients & $81(51.3)$ & $41(25.9)$ & $26(16.5)$ & $9(5.7)$ & 277 \\
\hline Avoided media news about COVID-19 and related fatalities & $123(77.8)$ & $23(14.6)$ & $8(5.1)$ & $3(1.9)$ & 205 \\
\hline Vented emotions by crying, screaming etc. & $139(88.0)$ & $13(8.2)$ & $3(1.9)$ & $2(1.3)$ & 182 \\
\hline
\end{tabular}

a For scoring purposes," not at all effective" $=1$ point; "mildly effective" $=2$ points; "moderately effective" $=3$ points; "extremely effective" $=4$ points

bor scoring purposes," never used" $=1$ point; "sometimes used" $=2$ points; "often used" $=3$ points; "always used" $=4$ points

35]. Health authorities and healthcare institutions should continue to ensure that PCPs are well provisioned not only with PPEs, but also accurate and timely information on COVID-19's disease characteristics, transmission mechanics, as well as best practices to protect themselves, fellow medical colleagues, and - indirectly - their loved ones during this pandemic. Healthcare institutions should also seek to monitor their PCPs' mental health and provide stress management services; as mentioned earlier in the discussion, studies post-SARS have cautioned that PCPs and other healthcare professionals directly involved with outbreak management are at heightened risk of psychological distress or post-traumatic stress disorder [26, $36,37]$. Stress management strategies could take the form 
of both formal and informal peer support groups, crisis counselling hotlines, or provisions for personal as well as group mindfulness exercises [35, 38].

\section{Limitations and implications for future research}

As this study was designed to meet the expediencies of the ongoing COVID-19 pandemic, several key limitations must be taken into consideration. Most significantly, the generalisability of our findings is limited by the non-random sampling strategy employed and the low response rate. This was perhaps expected due to the frontline and high intensity nature of PCPs' roles as outbreak control efforts continue to implemented in Singapore, and we recognize that our findings may only represent PCPs who were able to find the time to respond amidst their hectic schedules.

We also recognize that the quantitative descriptive nature of the present study could mean that PCPs may have had other concerns that were not included in our questionnaire. We were also unable to qualitatively probe the stress-reduction and coping strategies to understand the opinions of PCPs on how the government or healthcare institutions might be able to better support their needs. Lastly, as this study was conducted while community cases of COVID-19 were on the rise, we elected to focus on PCPs' existing concerns, coping strategies and preparedness, and did not probe their possible motivators to continue serving in future outbreaks.

Future studies could seek to overcome some of these limitations by implementing a more rigorous, probabilistic sampling strategy and utilizing mixed-methods designs to include qualitative interviews with PCPs. Nonetheless, the feasibility of these suggestions will inevitably depend on the progress of the COVID-19 pandemic in Singapore and around the world; social distancing measures and overwhelmed healthcare systems, for example, may prove to be immense challenges in conducting research with PCPs or other healthcare professionals.

\section{Conclusions}

The COVID-19 pandemic seems to show no signs of any return to normalcy in healthcare within the near future, and primary care must - by necessity - remain on the frontlines of any national outbreak control strategy. We conclude by reiterating the Commission on a Global Health Risk Framework for the Future's recommendation that primary care is inseparable with public health efforts in any pandemic, for a health system without effective and resilient primary care capabilities will lack the critical ability to quickly identify cases and mount a suitable infection prevention response [10]. While PCPs continue to profess a steadfast commitment to pandemic preparedness and medical professionalism during such trying times, health systems should strive to ensure that their psychosocial and professional needs are well taken care of holistically.

\section{Supplementary Information}

The online version contains supplementary material available at https://doi. org/10.1186/s12875-021-01370-7.

Additional file 1.

\section{Abbreviations}

WHO: World Health Organisation; COVID-19: Coronavirus Disease 2019; PCP: Primary care physician; PHPC: Public Health Preparedness Clinic; PPE: Personal protective equipment; SARS: Severe Acute Respitatory Syndrome; MERS-CoV: Middle Easten Respiratory Syndrome; NUHS: National University Health System; PCN: Primary Care Network; NUP: National University Polyclinics; CFPS: College of Family Physicians Singapore; DORSCON: Disease Outbreak Response System Condition

\section{Acknowledgements}

Not applicable.

\section{Authors' contributions}

$J$, DHYT, YJL, YXC, SEST, and KKT conceptualised the study. JL, DHYT, GJW, LLL, HKH, TSK, and KKT coordinated the collection of data. JL and GJW managed and analysed the data. $J$ drafted the initial manuscript. All authors read, edited, and approved the final manuscript.

\section{Funding}

This study was supported by the Singapore Population Health Improvement Centre (SPHERiC) [NMRC/CG/C026/2017_NUHS]. The funders had no role in the design of the study; collection, analysis or interpretation of data; writing of the manuscript; or decision to submit the manuscript for publication.

\section{Availability of data and materials}

The datasets used and/or analysed during the current study are available from the corresponding author on reasonable request.

Ethics approval and consent to participate

Ethical approval to conduct this study was provided by the National University of Singapore's Institutional Review Board (Reference Code S-20071) in accordance with the Declaration of Helsinki. Written informed consent to participate was obtained from all participants.

Consent for publication Not applicable.

\section{Competing interests}

The authors declare that they have no competing interests.

\section{Author details}

${ }^{1}$ Saw Swee Hock School of Public Health, National University of Singapore, Singapore, Singapore. ${ }^{2}$ Singapore Population Health Improvement Centre (SPHERiC), National University Health System, Singapore, Singapore. ${ }^{3}$ National University Polyclinics, Singapore, Singapore. ${ }^{4}$ College of Family Physicians Singapore, Singapore, Singapore. ${ }^{5}$ Family Medicine and Continuing Care, Singapore General Hospital, Singapore, Singapore. ${ }^{6}$ Outram Community Hospital, SingHealth Community Hospitals, Singapore, Singapore. ${ }^{7}$ Regional Health System Office, National University Health System, Singapore, Singapore. ${ }^{8}$ Primary Care Network, National University Health System, Singapore, Singapore. ${ }^{9}$ Yong Loo Lin School of Medicine, National University of Singapore, NUHS Tower Block, Level 8, 1E Kent Ridge Road, Singapore 119228, Singapore. 
Received: 6 July 2020 Accepted: 7 January 2021

Published online: 16 January 2021

\section{References}

1. World Health Organization. Coronavirus Disease 2019 (COVID-19) Weekly Epidemiological Update - 24 November 20202020 [https:/www.who.int/ emergencies/diseases/novel-coronavirus-2019/situation-reports/. Accessed: 25 Nov 2020].

2. Wong TY, Koh GC, Cheong SK, Sundram M, Koh K, Chia SE, et al. A crosssectional study of primary-care physicians in Singapore on their concerns and preparedness for an avian influenza outbreak. Ann Acad Med Singap. 2008;37(6):458-64.

3. Ministry of Health Singapore. Primary care survey 20142014 [https://www. moh.gov.sg/docs/librariesprovider5/resources-statistics/reports/moh-primarycare-survey-2014-report.pdf. Accessed: 3 Apr 2020].

4. Primary Care Pages. MOH National Schemes: Public Health Preparedness Clinic (PHPC) 2019 [https://www.primarycarepages.sg/practicemanagement/moh-national-schemes/public-health-preparedness-clinic(phpc). Accessed: 3 Apr 2020].

5. Ministry of Health Singapore. Primary Healthcare Services 2019 [https:// www.moh.gov.sg/home/our-healthcare-system/healthcare-services-andfacilities/primary-healthcare-services. Accessed: 3 Apr 2020].

6. Ministry of Health Singapore. Past Updates on COVID-19 Local Situation 2020 [https://www.moh.gov.sg/covid-19/past-updates. Accessed: 3 Apr 2020].

7. Ministry of Health Ontario. COVID-19 Guidance: Primary Care Providers in a Community Setting. 2020.

8. Public Health England. COVID-19: Interim guidance for primary care 2020 [https://www.gov.uk/government/publications/wn-cov-guidance-for-primarycare/wn-cov-interim-guidance-for-primary-care. Accessed: 3 Apr 2020].

9. Razai MS, Doerholt K, Ladhani S, Oakeshott P. Coronavirus disease 2019 (covid-19): a guide for UK GPs. BMJ. 2020;368:m800.

10. The National Academy of Medicine. The neglected dimension of global security: a framework to counter infectious disease crises. Washington: The National Academies Press; 2016. p. 142.

11. Chee $Y$. Heroes and heroines of the war on SARS. Singap Med J. 2003:44(5): 221-8.

12. Wong JE, Leo YS, Tan CC. COVID-19 in Singapore-current experience: critical global issues that require attention and action. Jama. 2020;323:1243.

13. Bai $Y$, Lin C-C, Lin C-Y, Chen J-Y, Chue C-M, Chou P. Survey of stress reactions among health care workers involved with the SARS outbreak. Psychiatr Serv. 2004;55(9):1055-7.

14. Wong W, Lee A, Tsang K, Wong S. How did general practitioners protect themselves, their family, and staff during the SARS epidemic in Hong Kong? J Epidemiol Community Health. 2004:58(3):180-5.

15. Wong TY, Koh GC, Cheong SK, Lee HY, Fong YT, Sundram M, et al. Concerns, perceived impact and preparedness in an avian influenza pandemic--a comparative study between healthcare workers in primary and tertiary care. Ann Acad Med Singapore. 2008;37(2):96.

16. Abolfotouh MA, AIQarni AA, Al-Ghamdi SM, Salam M, Al-Assiri MH, Balkhy $\mathrm{HH}$. An assessment of the level of concern among hospital-based healthcare workers regarding MERS outbreaks in Saudi Arabia. BMC Infect Dis. 2017:17(1):4.

17. Khalid I, Khalid TJ, Qabajah MR, Barnard AG, Qushmaq IA. Healthcare workers emotions, perceived stressors and coping strategies during a MERSCoV outbreak. Clin Med Res. 2016;14(1):7-14

18. National University Health System. About NUHS: Corporate Profile 2020 [https://www.nuhs.edu.sg/About-NUHS/Pages/corporate-profile.aspx. Accessed: 3 Apr 2020].

19. National University Health System. Care in the Community: Primary Care Network 2020 [https://www.nuhs.edu.sg/Care-in-the-Community/LivingWell/Pages/Primary-Care-Network.aspx. Accessed: 3 Apr 2020].

20. National University Polyclinics. Corporate Profile 2019 [https://www.nup. com.sg/Pages/About\%20Us/about-us-corporate-profile.aspx. Accessed: 3 Apr 2020].

21. College of Family Physicians Singapore. Professional Development of the Family Physician n.d. [https://www.cfps.org.sg/programmes/professionaldevelopment-of-the-family-physician/. Accessed: 3 Apr 2020].

22. REDCap Consortium. REDCap 2020 [https://www.project-redcap.org/ Accessed: 3 Apr 2020]

23. Corp IBM. IBM SPSS statistics for windows, version 22.0. Armonk: IBM Corp; 2013.
24. Tavakol M, Dennick R. Making sense of Cronbach's alpha. Int J Med Educ. 2011;2:53-5.

25. Koh D, Lim MK, Chia SE, Ko SM, Qian F, Ng V, et al. Risk perception and impact of severe acute respiratory syndrome (SARS) on work and personal lives of healthcare Workers in Singapore What can we Learn? Med Care. 2005:43:676-82

26. Preti E, Di Mattei V, Perego G, Ferrari F, Mazzetti M, Taranto P, et al. The Psychological Impact of Epidemic and Pandemic Outbreaks on Healthcare Workers: Rapid Review of the Evidence. Curr Psychiatry Rep. 2020;22(8):43.

27. Matsuishi K, Kawazoe A, Imai H, Ito A, Mouri K, Kitamura N, et al. Psychological impact of the pandemic (H1N1) 2009 on general hospital workers in Kobe. Psychiatry Clin Neurosci. 2012;66(4):353-60.

28. Ministry of Health Singapore. MOH Pandemic Readiness and Response Plan for Influenza and Other Acute Respiratory Diseases 2014 [https://www.moh. gov.sg/docs/librariesprovider5/diseases-updates/interim-pandemic-planpublic-ver-_april-2014.pdf. Accessed: 3 Apr 2020].

29. Min AH. COVID-19 outbreak: what you need to know about the public health preparedness clinics. Channel News Asia; 2020.

30. Elhadi M, Msherghi A, Alkeelani M, Zorgani A, Zaid A, Alsuyihili A, et al. Assessment of healthcare Workers' levels of preparedness and awareness regarding COVID-19 infection in low-resource settings. Am J Trop Med Hyg. 2020:103(2):828-33.

31. Elhadi M, Msherghi A, Alkeelani M, Alsuyihili A, Khaled A, Buzreg A, et al. Concerns for low-resource countries, with under-prepared intensive care units, facing the COVID-19 pandemic. Infect Dis Health. 2020;25(4):227-32.

32. Tabah A, Ramanan M, Laupland KB, Buetti N, Cortegiani A, Mellinghoff J, et al. Personal protective equipment and intensive care unit healthcare worker safety in the COVID-19 era (PPE-SAFE): an international survey. J Crit Care. 2020;59:70-5.

33. Lee $S-H$, Juang $Y-Y$, Su $Y-J$, Lee $H-L$, Lin $Y-H$, Chao C-C. Facing SARS: psychological impacts on SARS team nurses and psychiatric services in a Taiwan general hospital. Gen Hosp Psychiatry. 2005;27(5):352-8.

34. Simonds A, Sokol D. Lives on the line? Ethics and practicalities of duty of care in pandemics and disasters. Eur Respir J. 2009;34(2):303-9.

35. Chan AO, Huak CY. Psychological impact of the 2003 severe acute respiratory syndrome outbreak on health care workers in a medium size regional general hospital in Singapore. Occup Med. 2004;54(3):190-6.

36. Kuriansky J. The psychosocial aspects of a deadly epidemic: what Ebola has taught us about holistic healing: what Ebola has taught us about holistic healing: ABC-CLIO; 2016

37. Verma S, Mythily S, Chan Y, Deslypere J, Teo E, Chong S. Post-SARS psychological morbidity and stigma among general practitioners and traditional Chinese medicine practitioners in Singapore. Ann Acad Med Singap. 2004;33(6):743-8.

38. Krasner MS, Epstein RM, Beckman H, Suchman AL, Chapman B, Mooney CJ, et al. Association of an educational program in mindful communication with burnout, empathy, and attitudes among primary care physicians. Jama. 2009:302(12):1284-93.

\section{Publisher's Note}

Springer Nature remains neutral with regard to jurisdictional claims in published maps and institutional affiliations.

Ready to submit your research? Choose BMC and benefit from:

- fast, convenient online submission

- thorough peer review by experienced researchers in your field

- rapid publication on acceptance

- support for research data, including large and complex data types

- gold Open Access which fosters wider collaboration and increased citations

- maximum visibility for your research: over $100 \mathrm{M}$ website views per year

At BMC, research is always in progress.

Learn more biomedcentral.com/submissions 